\title{
Cardiac software repeatability beyond correlations: Clinical outcomes matter
}

\author{
H. J. Harms, PhD, ${ }^{a}$ and M. Lubberink, $\mathrm{PhD}^{\mathrm{b}}$ \\ a Department of Nuclear Medicine \& PET Center, Aarhus University Hospital, Aarhus, Denmark \\ b Department of Surgical Sciences/Radiology, Uppsala University, Uppsala, Sweden
}

Received May 5, 2020; accepted May 6, 2020

doi: $10.1007 / \mathrm{s} 12350-020-02194-1$

\section{See related article, pp. 2745-2757}

One of the unique features of nuclear cardiology is its ability to image cardiac sympathetic innervation and denervation, both with MIBG planar scintigraphy or SPECT and with PET using ${ }^{11} \mathrm{C}$-hydroxyephedrine (HED). Ischemic or infarcted myocardial tissue may result in denervation and the area of denervation has been linked to the area at risk in acute ischemic injury. ${ }^{1}$ Denervated myocardium in turn creates a substrate that is sensitive to arrhythmic triggers which may lead to sudden cardiac death. ${ }^{2}$ This has formed the rationale behind imaging of myocardial innervation as prognostic marker in coronary artery disease and heart failure. Indeed, both global levels of $\mathrm{MIBG}^{3}$ and ${ }^{11} \mathrm{C}-\mathrm{HED}^{4}$ and regional abnormalities ${ }^{5,6}$ have been shown to be associated with adverse events in a variety of cardiac diseases.

Where innervation imaging might be of particular interest, however, is in attempting to predict arrhythmias and sudden cardiac death (SCD) specifically. Initial studies have shown that the region of denervation exceeds that of irreversibly damaged myocardium, ${ }^{1}$ and an animal model using a different PET tracer, ${ }^{11} \mathrm{C}$-epinephrine, suggested that arrhythmias are particularly prone to start in denervated but viable tissue. ${ }^{7}$ The primary treatment to prevent SCD is the implantation of implantable cardiac defibrillators (ICD), which aim to detect and terminate potentially life-threatening arrhythmias. Typically, patients with left-ventricular

Reprint requests: H. J. Harms, PhD, Department of Nuclear Medicine \& PET Center, Aarhus University Hospital, Aarhus, Denmark; hans.harms@clin.au.dk

J Nucl Cardiol 2021;28:2758-60.

1071-3581/\$34.00

Copyright (C) 2020 American Society of Nuclear Cardiology. ejection fraction (LVEF) $\leq 35 \%$ are considered for ICD placement and in these patients, the survival benefit of ICD placement has been shown extensively. However, LVEF is not at all a marker of conductive integrity of the heart and as a result, only $\sim 1$ in 3 patients will ever receive an appropriate ICD discharge. Clearly, the current selection criteria for ICD placement are insufficient and more sophisticated risk stratification tools, such as cardiac neuronal imaging, are required.

The degree of denervated myocardium as well as the degree of denervated but viable ("mismatch") tissue has been the topic of two prospective trials using ${ }^{11} \mathrm{C}$ HED PET. Of these trials, one showed a negative result ${ }^{8}$ in 74 subjects and another, the Prediction of ARrhythmic Events with Positron Emission Tomography (PAREPET) trial $^{6}$ showed clear predictive power of ${ }^{11} \mathrm{C}$ HED defect size in 204 patients. Notably, the PAREPET trial retrospectively defined risk factors $\left({ }^{11} \mathrm{C}-\mathrm{HED}\right.$ defect area $>38 \%$, LV end-diastolic volume index, creatinine levels, and lack of angiotensin inhibition therapy) for cardiac death and subjects with no risk factors had low event rates $(<1 \%)$, similar to that of patients generally considered ineligible for ICD placement. In a subsequent analysis of the PAREPET trial, ${ }^{11} \mathrm{C}$-HED defect size was associated specifically with SCD and not at all with non-sudden (i.e., heart failurerelated) cardiac death, ${ }^{9}$ again suggesting that limited ${ }^{11} \mathrm{C}$-HED defect areas can be used to rule out increased risk of SCD independent of standard cardiac risk markers.

For innervation imaging to be accepted as tool to enter clinical practice, it is important that reproducibility of the tool as well as of the analysis process are known and high. The PAREPET trial was analyzed using the FlowQuant software package, a non-commercial software package developed at the University of Ottawa Heart Institute, an academic center. It made use of a defect score, multiplying the extent and severity of the myocardium $<75 \%$ of a reference region with the 
severity of the defect. This score has not been tested extensively in literature and has not been available in commercially available software packages, an important requirement for ultimate clinical use of denervation score. For other cardiac PET applications, mainly myocardial blood flow (MBF) and flow reserve (MFR), the impact of different software implementations on global values is known. ${ }^{10-13}$ However, the downstream effects of using different software packages on image interpretation and outcome analysis has been studied much less extensively, with only a brief description of agreement in MFR interpretation in one of these studies. ${ }^{11}$ Even though correlations of obtained MFR values were excellent $\left(r^{2}=0.95\right)$, agreement between three tested packages was only $84 \%$. Clearly, an inter-software or inter-observer correlation coefficient of global values is a very limited measure of practical reproducibility of any quantitative PET measure.

In this issue of the Journal of Nuclear Cardiology, Wang et al. ${ }^{14}$ put the ${ }^{11} \mathrm{C}$-HED defect score to the test by comparing the quantitative values between observers and two software packages. The authors used the original FlowQuant software used in the PAREPET trial as well as a commercially available package Corridor4DM which will be used in the PAREPET II trial (NCT03493516). This trial makes use of ${ }^{18}$ F-LMI1195 and the cut-off values and prognostic markers defined in the first PAREPET trial. The data of all 178 patients of the PAREPET trial that had evaluable ${ }^{11} \mathrm{C}$-HED images were analyzed by three observers without prior experience in cardiac image analysis. One observer analyzed the data twice in FlowQuant, one twice in Corridor4DM and one analyzed the data once in both packages. In addition, this study compares observer variability to actual test-retest variability in 20 different subjects, and studies to what extent the main findings of the PAREPET trial were reproduced with a re-analysis in either software package.

Not surprisingly, observer and software-related reproducibility was high with reproducibility coefficients (RPC) of $4.7 \%-6.3 \%$. This is in line with or improved compared to other cardiac PET applications $^{10-13}$ and illustrates the advances made by the various PET analysis software packages, which to a very large degree have become automated and standardized. This shows that the technique is safe even in the hands of novice observers. However, in this study, the results can be compared to actual test-retest reproducibility data, which showed an RPC of 10\%-11\% when analyzed by some of the same observers. With these data, it can finally be concluded that variation between scans is only marginally determined by differences in observers or software packages and are mostly from a technical (i.e., acquisition) or physiological origin.
In addition to this finding, the authors prospectively applied the cut-off for high-risk as defined in the main PAREPET paper to the re-analyzed data in either software package. The cut-off provided results in the rate of sudden cardiac arrest (SCA) consistent with that of the original PAREPET study. In addition, patients without risk factors for SCA, of which ${ }^{11} \mathrm{C}-\mathrm{HED}$ defect was one, had a very low rate of events irrespective of who analyzed the ${ }^{11} \mathrm{C}-\mathrm{HED}$ images and in which software package. This is important to confirm, as correlation coefficients or repeatability coefficients between two analyses do not necessarily represent useful values. For instance, when simulating MFR values ranging between 1 and 3 and the software variability for as reported for ${ }^{82} \mathrm{Rb}^{11}\left(r^{2}=0.93\right)$, as many as $6.4 \%$ of patients were reclassified from MFR $<2$ to MFR $>2$ or vice versa. The final clinical implications of such reclassification are not known but can be highly relevant. It is therefore important that Wang et al studied the downstream effects of different software packages on the PAREPET outcomes, and that the authors confirmed the robustness of those data.

In summary, this study by Wang et al shows the excellent reproducibility of denervation defect score quantification and it sets the bar for how software comparison studies have to be conducted, by including clinical outcome data as well as test-retest data. While the clinical value of innervation imaging has to be demonstrated unequivocally in clinical trials with prospectively defined risk factors (i.e., defect $>37.6 \%$ ), the analysis is robust and can be rolled-out immediately upon acceptance.

\section{Disclosures}

Both authors are working co-founders of MedTrace Pharma A/S, Lyngby, Denmark

\section{References}

1. Matsunari I, Schricke U, Bengel FM, Haase HU, Barthel P, Schmidt $\mathrm{G}$, et al. Extent of cardiac sympathetic neuronal damage is determined by the area of ischemia in patients with acute coronary syndromes. Circulation 2000;101:2579-85.

2. Tomaselli GF, Zipes DP. What causes sudden death in heart failure? Circ Res 2004;95:754-63.

3. Jacobson AF, Senior R, Cerqueira MD, Wong ND, Thomas GS, Lopez VA, et al. Myocardial iodine-123 meta-iodobenzylguanidine imaging and cardiac events in heart failure. Results of the prospective ADMIRE-HF (AdreView Myocardial Imaging for Risk Evaluation in Heart Failure) study. J Am Coll Cardiol 2010;55:2212-21.

4. Pietilä M, Malminiemi K, Ukkonen $H$, Saraste $M$, Någren K, Lehikoinen $\mathrm{P}$, et al. Reduced myocardial carbon-11 hydroxyephedrine retention is associated with poor prognosis in chronic heart failure. Eur J Nucl Med 2001;28:373-6. 
5. Boogers MJ, Borleffs CJ, Henneman MM, van Bommel RJ, Van RJ, Boersma E, et al. Cardiac sympathetic denervation assessed with 123-iodine metaiodobenzylguanidine imaging predicts ventricular arrhythmias in implantable cardioverter-defibrillator patients. J Am Coll Cardiol 2010;55:2769-77.

6. Fallavollita JA, Heavey BM, Luisi AJ, Michalek SM, Baldwa S, Mashtare TL, et al. Regional myocardial sympathetic denervation predicts the risk of sudden cardiac arrest in ischemic cardiomyopathy. J Am Coll Cardiol 2014;63:141-9.

7. Sasano T, Abraham MR, Chang KC, Ashikaga H, Mills KJ, Holt $\mathrm{DP}$, et al. Abnormal sympathetic innervation of viable myocardium and the substrate of ventricular tachycardia after myocardial infarction. J Am Coll Cardiol 2008;51:2266-75.

8. Rijnierse MT, van der Lingen A-LCJ, de Haan S, Becker MAJ, Harms HJ, Huisman MC, et al. Value of CMR and PET in predicting ventricular arrhythmias in ischemic cardiomyopathy patients eligible for ICD. JACC Cardiovasc Imaging 2020.

9. Fallavollita JA, Dare JD, Carter RL, Baldwa S, Canty JM. Denervated myocardium is preferentially associated with sudden cardiac arrest in ischemic cardiomyopathy: A pilot competing risks analysis of cause-specific mortality. Circ Cardiovasc Imaging 2017; 10:e006446.

10. Harms HJ, Nesterov SV, Han C, Danad I, Leonora R, Raijmakers $\mathrm{PG}$, et al. Comparison of clinical non-commercial tools for automated quantification of myocardial blood flow using oxygen15-labelled water PET/CT. Eur Heart J Cardiovasc Imaging 2014;15:431-41.

11. DeKemp RA, Declerck J, Klein R, Pan X-BB, Nakazato R, Tonge $\mathrm{C}$, et al. Multisoftware reproducibility study of stress and rest myocardial blood flow assessed with 3D dynamic PET/CT and a 1tissue-compartment model of $82 \mathrm{Rb}$ kinetics. J Nucl Med 2013;54:571-7.

12. Slomka PJ, Alexanderson E, Jácome R, Jiménez M, Romero E, Meave A, et al. Comparison of clinical tools for measurements of regional stress and rest myocardial blood flow assessed with $13 \mathrm{~N}$ ammonia PET/CT. J Nucl Med 2012;53:171-81.

13. Nesterov SV, Deshayes E, Sciagrà R, Settimo L, Declerck JM, Pan $\mathrm{XB}$, et al. Quantification of myocardial blood flow in absolute terms using $82 \mathrm{Rb}$ PET imaging the RUBY-10 study. JACC Cardiovasc Imaging 2014;7:1119-27.

14. Wang JZ, Moody JB, Kaps N, Britt D, Lavallee A, Renaud JM, et al. Reproducible quantification of regional sympathetic denervation with [11C]meta-hydroxyephedrine PET imaging. J Nucl Cardiol 2020. https://doi.org/10.1007/s12350-020-02114-3.

Publisher's Note Springer Nature remains neutral with regard to jurisdictional claims in published maps and institutional affiliations. 